ORNL/TM-2021/1942

IDMS\# 025280

\title{
TCR Data Management Plan
}

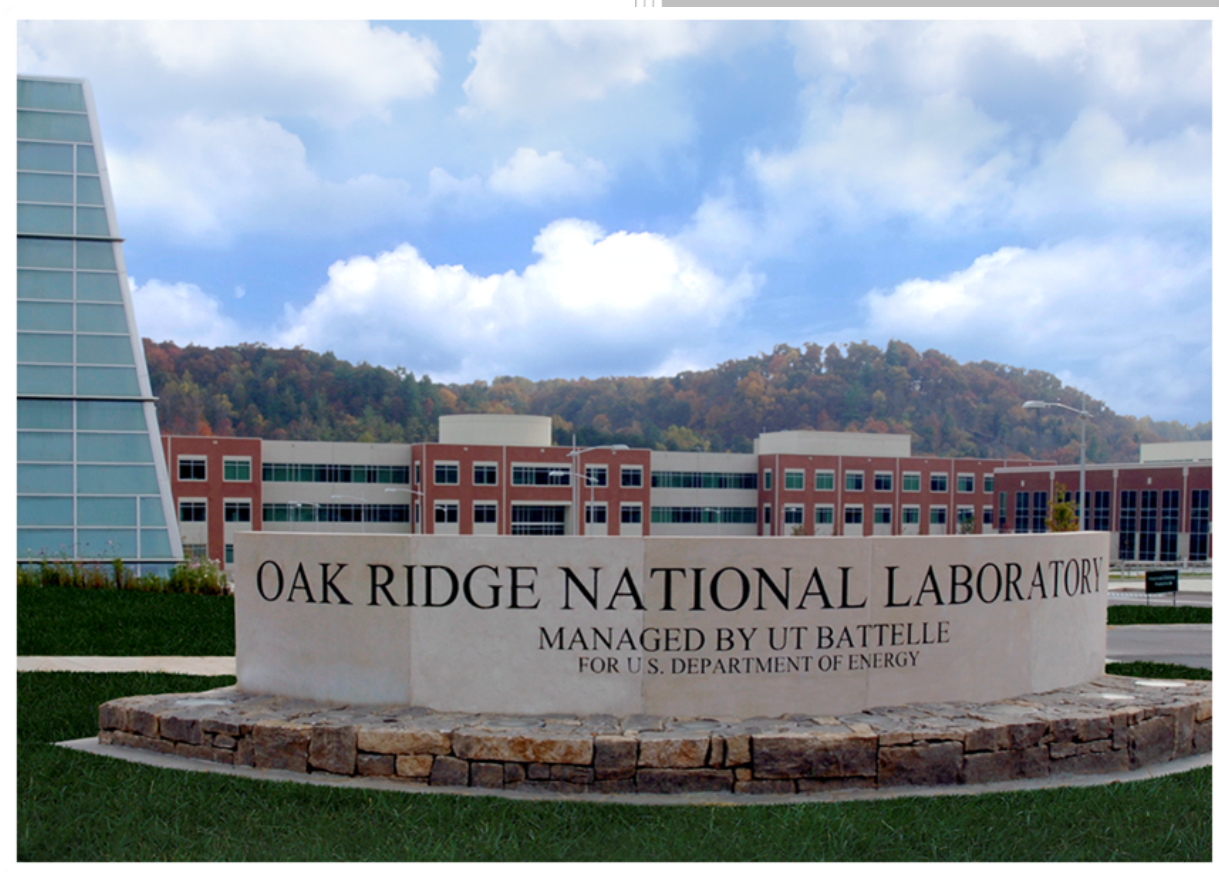

Michael Russell

Vincent Paquit

Alka Singh

Luke Scime

March 2021 


\title{
DOCUMENT AVAILABILITY
}

Reports produced after January 1, 1996, are generally available free via US Department of Energy (DOE) SciTech Connect.

\section{Website www.osti.gov}

Reports produced before January 1, 1996, may be purchased by members of the public from the following source:

\author{
National Technical Information Service \\ 5285 Port Royal Road \\ Springfield, VA 22161 \\ Telephone 703-605-6000 (1-800-553-6847) \\ TDD 703-487-4639 \\ Fax 703-605-6900 \\ E-mail info@ntis.gov \\ Website http://classic.ntis.gov/
}

Reports are available to DOE employees, DOE contractors, Energy Technology Data Exchange representatives, and International Nuclear Information System representatives from the following source:

Office of Scientific and Technical Information

PO Box 62

Oak Ridge, TN 37831

Telephone 865-576-8401

Fax 865-576-5728

E-mail reports@osti.gov

Website http://www.osti.gov/contact.html

This report was prepared as an account of work sponsored by an agency of the United States Government. Neither the United States Government nor any agency thereof, nor any of their employees, makes any warranty, express or implied, or assumes any legal liability or responsibility for the accuracy, completeness, or usefulness of any information, apparatus, product, or process disclosed, or represents that its use would not infringe privately owned rights. Reference herein to any specific commercial product, process, or service by trade name, trademark, manufacturer, or otherwise, does not necessarily constitute or imply its endorsement, recommendation, or favoring by the United States Government or any agency thereof. The views and opinions of authors expressed herein do not necessarily state or reflect those of the United States Government or any agency thereof. 
Transformational Challenge Reactor

\title{
TCR Data Management Plan
}

\author{
Michael Russell \\ Vincent Paquit \\ Luke Scime \\ Alka Singh
}

Date Published:

March 2021

\author{
Prepared by \\ OAK RIDGE NATIONAL LABORATORY \\ Oak Ridge, TN 37831-6283 \\ managed by \\ UT-BATTELLE, LLC \\ for the \\ US DEPARTMENT OF ENERGY \\ under contract DE-AC05-00OR22725
}




\begin{abstract}
The Oak Ridge National Laboratory (ORNL) Transformation Challenge Reactor (TCR) program is developing additive manufacturing and artificial intelligence (AI) to deliver enabling technologies for advanced reactors. Through the application of these advanced technologies, the program targets delivering solutions to the high costs and lengthy deployment timelines that threaten the future of nuclear energy - the country's largest source of carbon-free energy. This document describes the plan for integrating and managing TCR data from multiple sources throughout ORNL and external sources, including novel data sources associated with advanced manufacturing, characterization systems, and the TCR Digital Platform that incorporates various levels of AI and data analytics.
\end{abstract}




\section{OAK RIDGE NATIONAL LABORATORY}

MANAGED BY UT-BATTELLE FOR THE US DEPARTMENT OF ENERGY

\section{Transformational Challenge Reactor Program}

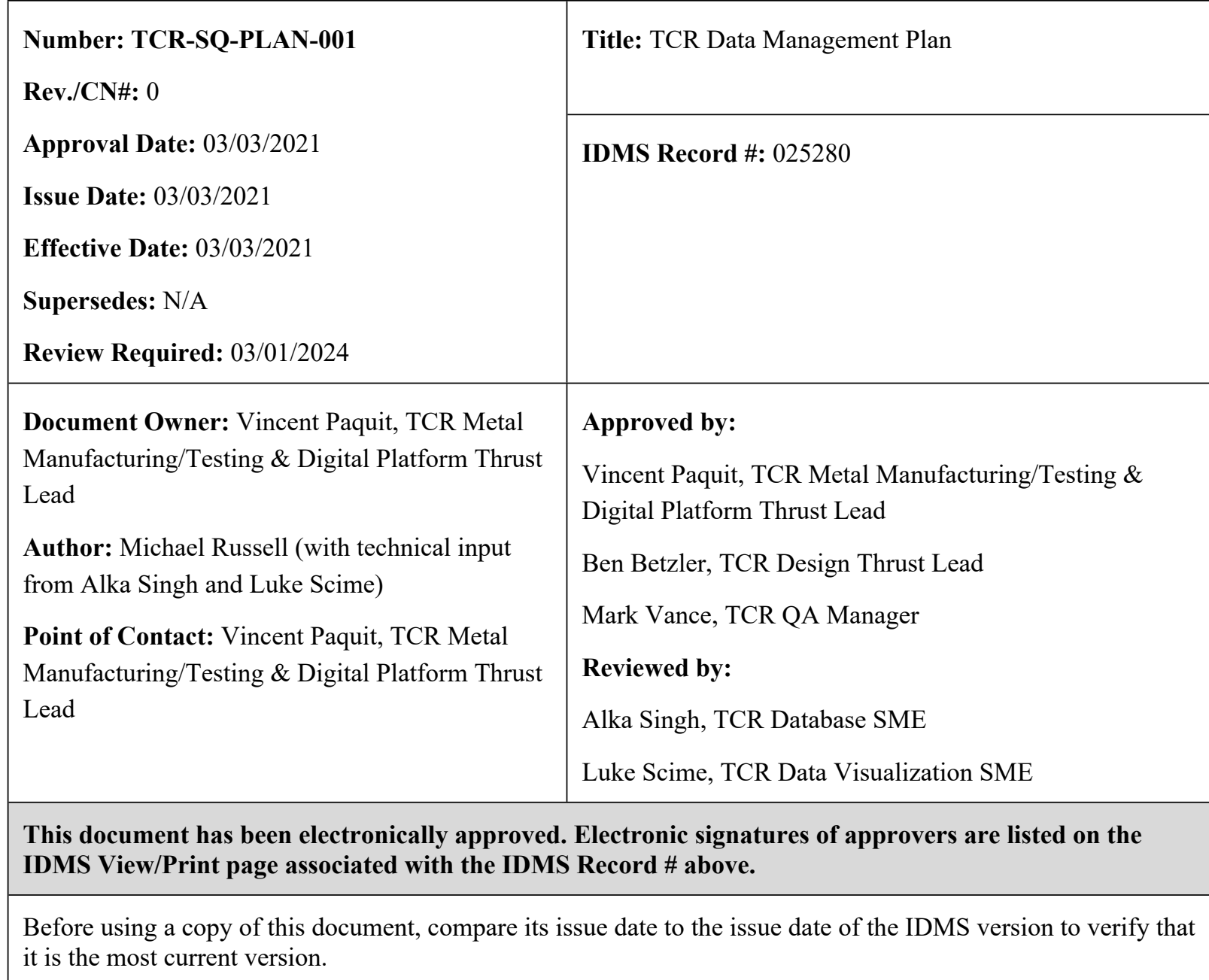




\section{REVISION LOG}

\begin{tabular}{|c|l|l|l|}
\hline Rev. & Date & Affected Pages & Revision Description \\
\hline 0 & $03 / 03 / 2021$ & All & Initial release \\
\hline & & & \\
\hline & & & \\
\hline & & & \\
\hline
\end{tabular}

\section{Document pages that are (check as appropriate):}

$\begin{array}{llll}\text { Unclassified, Non-Sensitive: } & \mathbf{X} & \text { ALL } & \text { (or) pages } \\ \text { Export Controlled: } & \text { NONE } & \text { (or) pages } \\ \text { Controlled, Unclassified, or Sensitive: } & \text { NONE } & \text { (or) pages }\end{array}-$

This document was prepared as an account of work sponsored by an agency of the United States Government. Neither the United States Government nor any agency thereof, nor any of their employees, makes any warranty, express or implied, or assumes any legal liability or responsibility for the accuracy, completeness, or usefulness of any information, apparatus, product, or process disclosed, or represents that its use would not infringe privately owned rights. Reference herein to any specific commercial product, process, or service by trade name, trademark, manufacturer, or otherwise, does not necessarily constitute or imply its endorsement, recommendation, or favoring by the United States Government or any agency thereof. The views and opinions of authors expressed herein do not necessarily state or reflect those of the United States Government or any agency thereof. 


\section{Table of Contents}

1. PURPOSE, SCOPE, AND APPLICABILITY

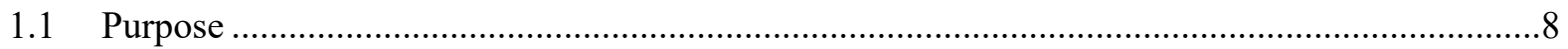

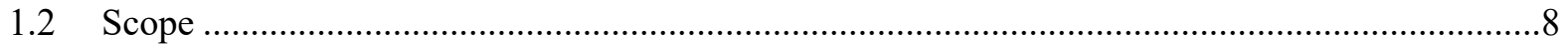

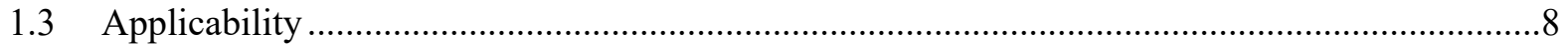

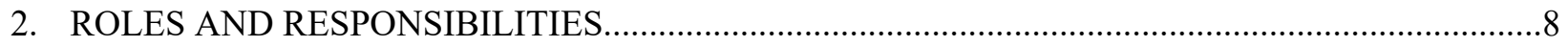

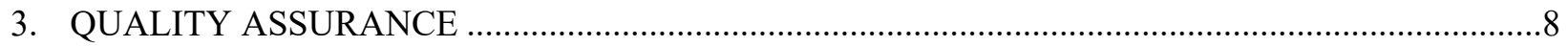

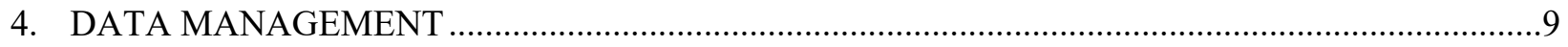

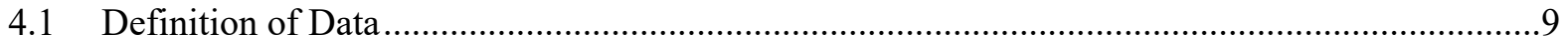

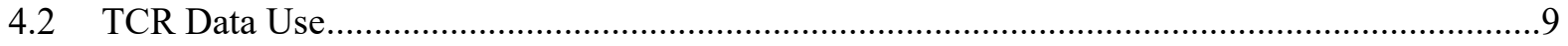

4.3 Use of DMPTool to Register ORNL Data Management Plan .................................................10

4.4 Types, Sources, and Storage of Data and Metadata ................................................................ 10

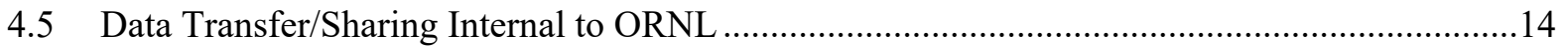

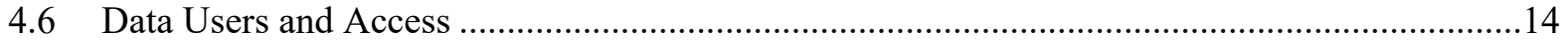

4.7 Data Maintenance (Including Schedule, Redundancy, and Backup) .......................................15

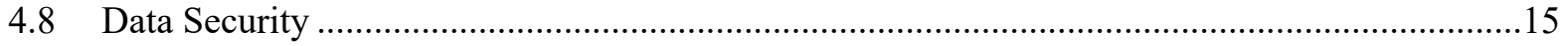

4.9 Export Control, Personally Identifiable Information, and Other Sensitivity Controls ................16

4.10 Data Sharing and Transfer External to ORNL .....................................................................16

4.11 Data Archive/Long-term storage ......................................................................................

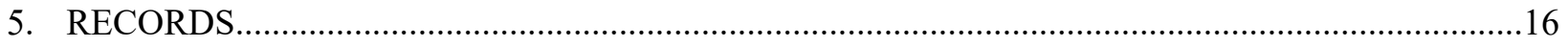

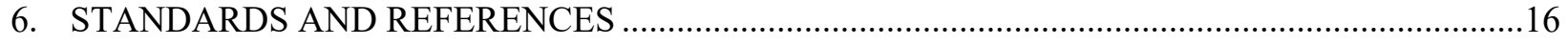

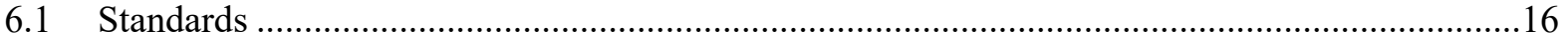

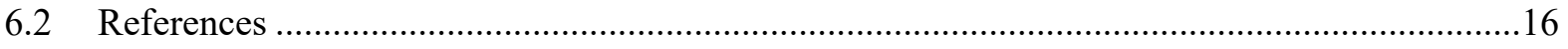

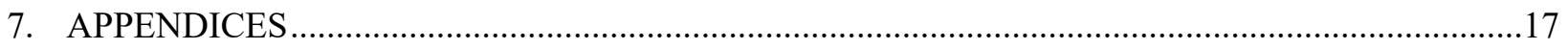

Appendix A: Abbreviations and Definitions ............................................................................ 18 


\begin{tabular}{|l|l|l|}
\hline TCR PLAN & TCR Data Management Plan & $\begin{array}{l}\text { TCR-SQ-PLAN-001 } \\
\text { Rev./CN\#: 0 } \\
\text { Page } 4 \text { of } 14\end{array}$ \\
\hline
\end{tabular}

\section{PURPOSE, SCOPE, AND APPLICABILITY}

\subsection{Purpose}

This plan describes the management requirements and processes to develop, store, secure, access, transfer, maintain, share, and preserve electronic and physical data at the Oak Ridge National Laboratory (ORNL) Transformational Challenge Reactor (TCR) Program. This plan will be updated periodically to ensure appropriate data controls are applied as the program matures.

\subsection{Scope}

This plan includes electronic and hardcopy data developed in support of the TCR program, including scientific research, engineering, safety analysis, simulation, design, manufacturing, characterization, calculations, irradiation/testing, handbook, lab notebooks, and related information.

\subsection{Applicability}

This plan applies to ORNL and partner organizations and staff developing, using, maintaining, and/or sharing TCR-related data and information.

\section{ROLES AND RESPONSIBILITIES}

- Data Manager (TCR Digital Platform Thrust Lead): Serves as the data manager for TCR and is responsible for the development, approval, and maintenance of this plan and the associated TCR-related data and related information. Specific data management duties can be delegated, but the overall responsibility and ownership resides with the TCR digital platform thrust lead.

- Database (DB) Subject Matter Expert (SME)/Administrator: Responsible for implementing this plan and maintaining data and related information/documentation according to this plan and applicable procedures, including TCR-SQ-PROC-001, "TCR Software Quality Assurance."

- Data Owner/User: Responsible for implementing the requirements of data management, including maintaining data security and backups, according to this plan and applicable procedures.

- TCR Quality Manager/Representative: Responsible for TCR data management oversight, including the implementation of applicable quality assurance (QA) and software quality assurance (SQA) requirements and program assessments.

- Office of the Chief Information Officer (OCIO): Responsible for management and oversight of the ORNL Unclassified Cyber Security Program Plan (CSPP).

\section{QUALITY ASSURANCE}

This plan was developed under ASME NQA-1-2008/9a, Quality Assurance Requirements for Nuclear Facility Applications including 2009 addendum, as implemented by TCR-QA-PLAN-001, Quality Assurance Program Plan for the Transformational Challenge Reactor Activities Conducted at Oak Ridge National Laboratory.

This plan is used in conjunction with TCR-SQ-PROC-001, "TCR Software Quality Assurance," and was developed under TCR-PM-PROC-001, "TCR Document Control and Records Management." The DOE Policy for Digital Research Data Management and the Suggested Elements for a Data Management Plan were used as references for the content included in this plan. 


\begin{tabular}{|l|l|l|}
\hline TCR PLAN & TCR Data Management Plan & $\begin{array}{l}\text { TCR-SQ-PLAN-001 } \\
\text { Rev./CN\#: 0 } \\
\text { Page 5 of 14 }\end{array}$ \\
\hline
\end{tabular}

ORNL data management planning is described under Standards-Based Management System (SBMS) subject area (SBJ), Work Control. Data protection is described under SBMS SBJ, Information Protection. Unclassified nuclear information is controlled per DOE Order 471.1B, Identification and Protection of Unclassified Controlled Nuclear Information, in conjunction with the Oak Ridge National Laboratory Controlled Unclassified Information Protection and Control Manual.

The TCR QA manager/representatives are responsible for TCR data management oversight, including implementation of applicable QA and SQA requirements and program assessments.

\section{DATA MANAGEMENT}

\subsection{Definition of Data}

Per the DOE Policy for Digital Research Data Management, the term digital data can be defined as the following:

The term digital data encompasses a wide variety of information stored in digital form including: experimental, observational, and simulation data; codes, software and algorithms; text; numeric information; images; video; audio; and associated metadata. It also encompasses information in a variety of different forms including raw, processed, and analyzed data, published and archived data.

This policy focuses on digital research data, which are research data that can be stored digitally and accessed electronically. Research data are defined in regulation 2 CFR 200.315 (e), continuing the definition from 2 CFR 215 (OMB Circular A-110) as follows:

"Research data is defined as the recorded factual material commonly accepted in the scientific community as necessary to validate research findings, but not any of the following: preliminary analyses, drafts of scientific papers, plans for future research, peer reviews, or communications with colleagues. This 'recorded' material excludes physical objects (e.g., laboratory samples). Research data also do not include:

(A) Trade secrets, commercial information, materials necessary to be held confidential by a researcher until they are published, or similar information which is protected under law; and

(B) Personnel and medical information (personally identifiable information (PII) and similar information the disclosure of which would constitute a clearly unwarranted invasion of personal privacy, such as information that could be used to identify a particular person in a research study."

\subsection{TCR Data Use}

The TCR program develops and uses technical data to support the development of novel nuclear technologies, including the use of additive manufacturing (AM), artificial intelligence digital platforms, unique nuclear fuel types, complex geometry reactor cores, advanced characterization tools, material testing, and ancillary support systems. TCR encompasses multiple ORNL directorates and technologies, thus using multiple computer and software platforms in multiple organizations to access, use, share, develop, and store technical data. The TCR digital platform thrust lead is assigned the primary duties as the TCR data manager and is responsible for all data management and access controls. TCR is developing a suite of software items, DBs, and technical handbook data that will be used initially internally to ORNL research and eventually shared with external organizations primarily by formal use or licensing agreements. 


\begin{tabular}{|l|l|l|}
\hline TCR PLAN & TCR Data Management Plan & $\begin{array}{l}\text { TCR-SQ-PLAN-001 } \\
\text { Rev./CN\#: 0 } \\
\text { Page 6 of } 14\end{array}$ \\
\hline
\end{tabular}

- Initial data developed as part of the TCR program are kept on various computer servers around the ORNL campus, according to the primary owning organization. TCR data that are specific to the digital platform and AM technology development and testing are housed on a TCR-managed server called SAVITAR located at the ORNL Manufacturing Demonstration Facility (MDF), which also houses many of the TCR management, software developers, and AM personnel. This data will be stored at ORNL as long as required to continue the support of TCR, related intellectual property, and licensees. The long-term preservation of TCR data after the completion of the TCR program will be evaluated with relevant stakeholders to determine the best location for long-term archival storage and/or disposition. Specific details, including links to the data storage locations, specific data types, file names, owners/contacts, and so on are maintained in the TCR Data Location and Owner Matrix separately from this document. This matrix is a living document and is maintained in the TCR SharePoint secured site with enhanced levels of access control.

\subsection{Use of DMPTool to Register ORNL Data Management Plan}

SBMS SBJ, Work Control, encourages the use of the DMPTool to develop portions of and register ORNL data management plans. TCR uses the ORNL Integrated Document Management System (IDMS) to develop planning documents in accordance with TCR-PM-PROC-001, "TCR Document Control and Records Management." This data management plan will be finalized under these controls in IDMS and is informed by the DMPTool and related required information. After completion and approval, this plan will be evaluated for inclusion in the DMPTool.

\subsection{Types, Sources, and Storage of Data and Metadata}

TCR data comprise multiple types, sources, and formats and are stored in various locations throughout ORNL. Typical types of TCR data include design documentation; drawings; specifications; analysis inputs/outputs; testing; manufacturing; chemical composition; heating profiles and exposures; AM design, build, and slicing (CAD/Standard Triangle Language [STLs]); machining; photos, videos, and images; graphics; inspection; log files; qualifications; laboratory results; and related metadata.

TCR data sources can include professional CAD and analysis software; AM, testing, and machining systems; characterization systems; heat treatment/chemical vapor infiltration furnaces; the digital platform; Peregrine; inspections; qualifications; training; external and internal laboratories; cameras; LabView software; and so on.

TCR data are primarily stored on ORNL servers located on the ORNL campus and/or at the MDF. Data storage locations include the ORNL SharePoint sites, ORNL OneNote (electronic lab notebooks), ORNL Dropbox, ORNL servers, individual computers, external hard drives and drive sticks, hardcopy notebooks, secured file cabinets, and so on. All of these storage locations are in ORNL facilities maintained by ORNL security and/or information technology personnel, as described in this plan.

\subsubsection{Reactor Core Design}

Reactor core design data include drawings, specifications, documents, and metadata associated with the TCR reactor core. These data are stored on ORNL servers within OneNote, SharePoint, Dropbox, or similar secured environments.

\subsubsection{Reactor Simulation and Analysis}

Reactor simulation and analysis data include inputs, raw data, and analyzed results of TCR reactor simulation and analysis software. These data are stored on ORNL servers 
within OneNote and SharePoint, Dropbox, or similar secured server environments.

\subsubsection{Reactor Systems and Balance of Plant}

TCR procures reactor systems and the balance of plant design and engineering functions from an external supplier. The design/engineering supplier is responsible for maintaining its TCR data in a secured and backed-up server environment until it can be transferred to TCR. These data comprise design drawings, specifications, analyses, test results, calculations, reports, and related metadata. This information is transferred through and stored in an ORNL-maintained SharePoint.

\subsubsection{Irradiation Testing}

TCR irradiation testing is conducted at multiple internal and external locations, including ORNL's hot cells, High-Flux Isotope Reactor (HFIR), and Spallation Neutron Source (SNS). These data include design drawings, specifications, analysis, test results, calculations, reports, and related metadata. External irradiation and testing are performed at Idaho National Laboratory (INL) Transient Reactor Test (TREAT), Argonne National Laboratory (ANL), Massachusetts Institute of Technology Reactor (MITR), University of Tennessee, Knoxville (UT), campus, and various other locations as needed to complete the TCR mission. Incoming and outgoing data are stored on ORNL servers within OneNote, SharePoint, Dropbox, or similar secured server environments. Per procurement requirements, external facilities are required to maintain test data with the same rigor, redundancy, controls, and protection as applied within ORNL.

\subsubsection{Reactor Instrument and Control}

TCR instrument and control (I\&C) data include design drawings/schematics, specifications, analysis, test results, and related metadata. These data are stored on ORNL servers within OneNote, SharePoint, Dropbox, or similar secured environments.

\subsubsection{Fuel, Material, Testing and System Simulation}

TCR nuclear fuel and moderator data include fuel specifications, production parameters, related materials, analysis testing, characterization, and simulation data. These data are stored on ORNL servers within OneNote, Dropbox, SharePoint, or similar secured environments.

\subsubsection{Characterization Systems}

Characterization data are highly diverse and include material composition measurements, powder and particle size distribution and morphology measurements, 2D optical microscopy images, 2D electron microscopy images and reconstructions, 3D optical microscopy reconstructions, 3D electron microscopy reconstructions, 3D x-ray computed tomography reconstructions, thermal conductivity measurements, 3D surface topology scans, manual point-to-point geometric measurements, pycnometric density measurements, component mass measurements, traditional macroscopic optical imaging, and metadata and observations collected by trained technicians. These data are typically large and are often expensive to generate, so only selected TCR parts will be subjected to most of these characterization efforts. No single TCR part is expected to undergo the totality of these characterization modalities. 
Material characterization and testing operations are conducted at multiple locations, including:

- MDF MetLab (e.g., mechanical testing),

- MDF Zeiss characterization lab (e.g., x-ray imaging, electron backscatter diffraction, coordinate measuring machine, microscopy),

- ORNL Materials Science and Technology Division labs on ORNL's main campus (e.g., x-ray imaging, mechanical tests, bust testing),

- ORNL HFIR (irradiation tests),

- MITR (irradiation tests),

- $\quad$ ANL (e.g., mechanical test, creep, fatigue),

- INL TREAT facility (irradiation tests),

- academia (e.g., UT, Purdue University, University of Michigan), and

- external laboratories (e.g., material, powder).

In each of these cases, the primary TCR thrust lead and associated ORNL principal investigator (PI) are responsible for ensuring that the associated TCR data are transferred and controlled according to this plan. Care is taken to ensure that all data that fall under export controls are managed and protected accordingly. These data-some of which are sourced from outside entities, testing, and/or analysis results - are then imported into ORNL and/or TCR data servers and managed accordingly.

\subsubsection{Mechanical Testing}

Mechanical testing data include specimen test parameters and results directly generated from the testing machines, including time, temperature, force, duration, and pictures. This information is initially captured directly on the test machine computer and then transferred by the network or manually to the digital platform for long-term storage and analysis.

\subsubsection{Additive Manufacturing Systems}

The AM systems in use for the TCR program build parts from 3D CAD models layer by layer. In all cases, these CAD models must first be converted into the STL file format. These STL files are then placed in 3D space within the printer build volume and sliced into layers. After slicing, laser scan vectors or printhead pass instructions are generated; this process is similar to toolpath generation for a subtractive machine. Typically, slicing and toolpath information are stored in a vendor-proprietary file format. Images of each slice of the STL geometry are also generated and used by various ORNL software tools, such as Peregrine. During and after the build, trained technicians record metadata, observations, and images and videos by using handheld cameras. Each additive system also generates varying types and quantities of in situ process monitoring data, which are enumerated as follows.

\subsubsection{ConceptLaserM2-ORNL1}

- Log files containing machine status and health information, recorded in a plain text file format. 
- Coaxially aligned photodiode and camera data for each laser module, recorded in the zipped National Instruments TDMS file format.

- Two images of the powder bed are captured per layer by using a 150 MP 16bit grayscale PhaseOne camera, recorded initially in the CaptureOne IIQ file format before conversion into the standard TIF image format.

\subsubsection{ConceptLaserXLine2000R-ORNL1}

- Log files containing machine status and health information, recorded in a plain text file format.

\subsubsection{ExOneInnovent-0137}

- Log files containing process parameter settings and machine status and health information, recorded in an RPT file format.

- Two images of the powder bed are captured per layer by using a 20 MP 8-bit grayscale Basler camera, recorded by Peregrine in the JPG image format.

\subsubsection{ExOneInnovent-0166}

- Log files containing process parameter settings and machine status and health information, recorded in an RPT file format.

- Two images of the powder bed are captured per layer by using a 20 MP 8-bit grayscale Basler camera, recorded by Peregrine in the JPG image format.

\subsubsection{Finishing, Cutting, Machining, and Cleaning Systems}

Metadata are currently being recorded for the Wire EDM operations performed by using the SodickAQ750LH-T0981 machine. Machining data (program) are maintained on the machine-specific computer and transferred to ORNL servers when required to be saved. No other data are currently being tracked for these operations for the TCR program.

\subsubsection{Curing, Stress Relief, and Heat Treatment}

Temperature profiles and time details are recorded in a spreadsheet format during stressrelief operations performed by the furnaces for the AM components. These data are captured in spreadsheet format directly from the furnace computer and then transferred to SAVITAR. No other data from heat treatment operations are currently being tracked for the TCR program.

\subsubsection{Fuel Loading and Chemical Vapor Infiltration Systems}

No data are currently being tracked for these operations for the TCR program.

\subsubsection{Quality Inspections}

Data collected specifically for post-manufacture component quality inspections include visual and dimensional inspection results, typically captured in a spreadsheet or similar table format. These data are provided to the digital platform and stored appropriately. Before being uploaded to the digital platform, the electronic records are temporarily stored on ORNL network servers that are backed up daily. 


\begin{tabular}{|l|l|l|}
\hline TCR PLAN & TCR Data Management Plan & $\begin{array}{l}\text { TCR-SQ-PLAN-001 } \\
\text { Rev./CN\#: } 0 \\
\text { Page } 10 \text { of } 14\end{array}$ \\
\hline
\end{tabular}

\subsection{Data Transfer/Sharing Internal to ORNL}

4.5.1 Reactor Design, Fuels, Analysis, Testing, Calculations, Simulation, and Testing Data

TCR data transfer, not specifically described in this plan, is performed over secure ORNL networks and/or is hand transferred by using portable computers and hard drives, USB flash drives, or similar methods. When required, these data are transferred electronically to the ORNL servers and/or digital platform and stored on the SAVITAR data server at the MDF. Data transfer is performed in conjunction with SBMS SBJ, Information Protection.

\subsubsection{Characterization Systems}

Some characterization data are stored on the SAVITAR data server at the MDF or on the main ORNL servers. These data are uploaded manually by using a mapped network drive. Much of the characterization data also remains at the point of generation or with the respective PIs. Characterization and monitoring data files can be very large, so only specific specimens and areas of interest are captured for longer term storage and inputs into the digital platform. The PI is responsible for backing up individual characterization computers by using an external hard drive or other means until the select data are transferred to SAVITAR.

\subsubsection{Additive Manufacturing Systems}

Non-export-controlled data from the AM systems are stored on the SAVITAR data server in the MDF TCR computer room. These data are stored within a common file system, which is managed by the Digital Tool web interface and the software tool Peregrine. Export-controlled (EC) data are stored on encrypted hard drives located in locked cabinets or desktop drive bays in the export-controlled office space at the MDF and in the MDF TCR computer room. Non-export-controlled data are transferred to SAVITAR via a combination of encrypted USB flash drives, encrypted portable hard drives, physical movement of desktop computers from the point of generation to the MDF TCR computer room, direct upload via Peregrine and a mapped network drive, and data entry and upload via the Digital Tool web interface. The data are automatically organized on SAVITAR by machine name/year/month/build name.

Metadata are stored within the DB by using PostgresSQL, a relational DB management system. The metadata are organized into schemas and further grouped together in relevant DB tables. The DB server currently runs on the SAVITAR data storage system.

\subsection{Data Users and Access}

TCR data are currently primarily used internally at ORNL and partner national laboratories to support TCR and related research and development programs. Access to TCR data is limited to users with a specific access need and ORNL credentials. Access to data is applied and approved on a hierarchical mechanism of lower to higher access levels being granted based on user requirements and TCR management approvals. Access to physical TCR computing resources is controlled by using proximity card reader-controlled doors, organization personnel, protective forces, and/or locks and keys. Eventually, external access to data might be required, which will require additional levels of access control and security for accommodation. Currently, any sharing of data outside of ORNL personnel is on a case-by-case basis and is assigned appropriate security and data-transfer protocols, including obtaining an export control license for the data or the software and code producing such data. 


\begin{tabular}{|l|l|l|}
\hline TCR PLAN & TCR Data Management Plan & $\begin{array}{l}\text { TCR-SQ-PLAN-001 } \\
\text { Rev./CN\#: } 0 \\
\text { Page } 11 \text { of } 14\end{array}$ \\
\hline
\end{tabular}

Specifically, the data and metadata collected for the TCR program are available internally for use by scripts, software tools, and personnel. Access to the data and metadata is granted to people and software after evaluating their need and usage of the data. Metadata access levels are stored and maintained by the PostgresSQL server, and user access is always validated before accessing the data. Data access privileges are also assigned after a detailed evaluation of the need to access data. Most data are accessible via a mapped network drive or through representational state transfer (REST) application programming interfaces (APIs) developed in Python. The following interfaces enable access to the metadata and data. Data access is controlled first by domain authentication and additionally by user-specific read and or write access to all or a portion of the $\mathrm{DB}$, the latter being controlled by the TCR DB SME or administrator.

- Digital Tool: A web-based application used primarily to collect and access metadata.

- REST APIs: These Python based APIs are used by software tools to access and retrieve data and metadata.

- Samba: This Server Message Block networking protocol is used to map network drives and access data on the SAVITAR data storage system.

\subsection{Data Maintenance (Including Schedule, Redundancy, and Backup)}

Data stored on the SAVITAR server at the MDF are backed up daily to the ZOOM server in Building 5600 on the ORNL campus approximately 7 miles away.

Individual ORNL technical contributors are required per ORNL's data management policy to maintain and preserve raw data on the source computer systems until they can be transferred to the appropriate server.

ORNL's main servers are backed up daily with redundant and backup systems located in separate facilities approximately $12 \mathrm{mi}$ from campus primary servers. Additional data maintenance information is contained in the ORNL Cyber Security Program Plan (CSPP).

Additional data maintenance information is contained in the ORNL CSPP. Specific TCR data types, sources, locations, and points of contact are maintained on a secured location of the TCR SharePoint site with limited access. This information will not be shared in this document but is available per request from the TCR data manager. Raw data acquired during testing or analysis actions could be initially captured on individual computers that might not be connected to network data servers. The data owner is responsible for maintaining and backing up this initial raw data on another computer, server, or storage device until it can be appropriately transferred to a TCR data storage server.

\subsection{Data Security}

TCR data security is applied as a multilevel hierarchy, which allows access approval to specific users/administrators only with a specific need and approval from the TCR data manager. The data is housed on ORNL servers that apply security protocols under ORNL's cybersecurity program and SBMS SBJ, Information Protection. Export controlled and similar International Traffic in Arms Regulations (ITAR) data is stored in access-controlled storage and only transferred utilizing a sanctioned ORNL encryption software.

Access to ORNL sites and specific TCR facilities is managed by the access control system operational 24 hours daily to limit access to authorized personnel and protect US Department of Energy (DOE) property and facilities. Access is controlled by using proximity card readercontrolled doors, organization personnel, protective forces, and/or locks and keys. Employees and 
visitors wear appropriate DOE-issued or visitor badges at all times. An intrusion detection system is used to detect unauthorized entry and/or presence in most facilities and systems. Security for ORNL data is outlined in the OCIO-CSPP-001, ORNL Unclassified Cyber Security Program Plan (CSPP) managed by the ORNL Office of the Chief Information Officer (OCIO). This plan described the overall cybersecurity approach and classification for all ORNL nonclassified computing assets, including those used by TCR. As such, the requirement and details outlined in that plan will not be repeated in this plan but are included as reference.

\subsection{Export Control, Personally Identifiable Information, and Other Sensitivity Controls}

Additional controls are applied to data that are considered EC, personally identifiable information, Official Use Only, Unclassified Controlled Nuclear Information, and so on. These controls include higher access controls and encryption for storing and sharing of data, along with vetting those allowed appropriate access.

\subsection{Data Sharing and Transfer External to ORNL}

Currently, there are no external-to-ORNL users of TCR data who have direct access to the TCR DBs. If an external organization requests access to the data or wants to share data, a special mechanism for sharing the data is developed and implemented on a case-by-case basis according to SBMS SBJ, Information Protection.

\subsection{Data Archive/Long-term storage.}

TCR data will be stored at ORNL as long as required to continue the support of TCR, related intellectual property, and licensees. The long-term preservation of TCR data after the completion of the TCR program will be evaluated with relevant stakeholders to determine the best location for long-term archival storage and/or disposition, if required. This plan will be updated periodically to ensure that appropriate data controls are applied as the program matures.

\section{RECORDS}

- Data Location and Owner Matrix

\section{STANDARDS AND REFERENCES}

\subsection{Standards}

- ASME NQA-1-2008/9a, Quality Assurance Requirements for Nuclear Facility Applications including 2009 addendum

- DOE Order 471.1B, Identification and Protection of Unclassified Controlled Nuclear Information

- DOE Policy for Digital Research Data Management

- OCIO-CSPP-001, ORNL Unclassified Cyber Security Program Plan (CSPP)

\subsection{References}

- SBMS SBJ, Work Control

- SBMS SBJ, Information Protection

- TCR-QA-PLAN-001, Quality Assurance Program Plan for the Transformational Challenge Reactor Activities Conducted at Oak Ridge National Laboratory

- TCR-PM-PROC-001, “TCR Document Control and Records Management” 


\begin{tabular}{|l|l|l|}
\hline TCR PLAN & TCR Data Management Plan & $\begin{array}{l}\text { TCR-SQ-PLAN-001 } \\
\text { Rev./CN\#: } 0 \\
\text { Page } 13 \text { of } 14\end{array}$ \\
\hline
\end{tabular}

- TCR-SQ-PROC-001, "TCR Software Quality Assurance”

7. APPENDICES

- Appendix A: Abbreviations and Definitions 


\section{Appendix A: Abbreviations and Definitions}

\begin{tabular}{|c|c|}
\hline \multicolumn{2}{|r|}{ Abbreviations } \\
\hline $\mathrm{AM}$ & additive manufacturing \\
\hline ANL & Argonne National Laboratory \\
\hline API & application programming interface \\
\hline DB & database \\
\hline DOE & US Department of Energy \\
\hline EC & export-controlled \\
\hline HFIR & High-Flux Isotope Reactor \\
\hline $\mathrm{I} \& \mathrm{C}$ & instrument and control \\
\hline IDMS & Integrated Document Management System \\
\hline INL & Idaho National Laboratory \\
\hline MDF & Manufacturing Demonstration Facility \\
\hline MITR & Massachusetts Institute of Technology Reactor \\
\hline ORNL & Oak Ridge National Laboratory \\
\hline PI & principal investigator \\
\hline QA & quality assurance \\
\hline REST & representational state transfer \\
\hline $\mathrm{SBJ}^{1}$ & subject area \\
\hline SBMS & Standards-Based Management System \\
\hline SME & subject matter expert \\
\hline SNS & Spallation Neutron Source \\
\hline SQA & software quality assurance \\
\hline STL & Standard Triangle Language \\
\hline TCR & Transformational Challenge Reactor \\
\hline TREAT & Transient Reactor Test \\
\hline $\mathrm{UT}$ & University of Tennessee, Knoxville \\
\hline
\end{tabular}

${ }^{1}$ This abbreviation is not part of a unique document identifier or document title. 